\title{
Antithrombin Alfa
}

National Cancer Institute

\section{Source}

National Cancer Institute. Antithrombin Alfa. NCI Thesaurus. Code C82234.

A recombinant form of human antithrombin with anticoagulant activity. Antithrombin alfa blocks thrombin activity and thus thrombus formation. It is used in patients with antithrombin deficiency. 